J. Amer. Soc. Hort. SCI. 121(5):794-803. 1996.

\title{
Molecular Markers Associated with Plant Architecture and Resistance to Common Blight, Web Blight, and Rust in Common Beans
}

\author{
Geunhwa Jung ${ }^{1}$ and Dermot P. Coyne \\ Department of Horticulture, University of Nebraska, Lincoln, NE 68583 \\ Paul W. Skroch and James Nienhuis \\ Department of Horticulture, University of Wisconsin, Madison, WI 53706 \\ E. Arnaud-Santana \\ Arroyo Loro Experiment Station, San Juan de la Maguana, Dominican Republic
}

James Bokosi and H.M. Ariyarathne

Department of Horticulture, University of Nebraska, Lincoln, NE 68583

James R. Steadman

Department of Plant Pathology, University of Nebraska, Lincoln, NE 68583

James S. Beaver

Department of Agronomy and Soils, University of Puerto Rico, Mayaguez, PR 00681

\author{
Shawn M. Kaeppler \\ Department of Agronomy, University of Wisconsin, Madison, WI 53706
}

Additional index words. random amplified polymorphic DNA, Xanthomonas campestris pv. phaseoli, Thanatephorus cucumeris, Uromyces appendiculatus, disease resistance

\begin{abstract}
Random amplified polymorphic DNA (RAPD) markers were used to construct a partial linkage map in a recombinant inbred population derived from the common bean (Phaseolus vulgaris L.) cross BAC 6 X HT 7719 for studying the genetics of disease resistance in common bean. The linkage map spanned $545 \mathrm{cM}$ and included 75 of 84 markers used in this study. The population of 128 recombinant inbred lines was evaluated for resistance to common bacterial blight, foliar resistance to web blight [WB; Thanatephorus cucumeris (Frank) Donk], and resistance to rust [Uromyces appendiculatus var. appendiculatus (Pers.:Pers) Unger]. Common bacterial blight [CBB; Xanthomonas campestris pv. phaseoli (Smith) Dye] resistance was evaluated for CBB strain Epif-IV in later-developed trifoliolate leaves and for CBB strain EK-11 in seeds, first trifoliolate leaves, later-developed trifoliolate leaves, and pods. In addition, lines were rated for plant uprightness and branch density. Two to six markers accounted for $14 \%$ to $34 \%$ of the phenotypic variation for each trait. Significant marker locustrait associations were found for 14 mapped loci and 7 of the 9 unmapped markers. The distribution of detected QTL appeared to be nonrandom with most significant markers associated with more than one trait or closely linked to markers significantly associated with variation for a different trait. One marker, $\mathrm{BC409}_{1250}$, was significantly associated with $\mathrm{WB}$ resistance, resistance for CBB strain Epif-IV in later-developed trifoliolate leaves, and resistance for CBB strain EK-11 in first trifoliolate leaves, later-developed trifoliolate leaves, and pods. A rust resistance gene was mapped in an interval $14.6 \mathrm{cM}$ from RAPD marker $\mathrm{H19}_{1050}$ and $12.5 \mathrm{cM}$ from marker $\mathrm{AJ}_{16}{ }_{250^{\circ}}$
\end{abstract}

Common bacterial blight (CBB; Xanthomonas campestris pv. phaseoli), web blight (WB; Thanatephorus cucumeris), and rust (Uromyces appendiculatus var. appendiculatus) are important diseases of common bean (Harter and Zaumeyer, 1944). These diseases cause economic losses due to a reduction in seed yield and seed quality in dry bean producing regions worldwide (Galvez et al., 1989; Saettler, 1989; Stavely and Pastor-Corrales, 1989). The most reliable and effective control strategy for these diseases is the

Received for publication 5 Dec. 1995. Accepted for publication 22 Apr. 1996 Nebraska Agricultural Research Division journal series paper no. 11318. Research was conducted under projects 20-036 and 20-042. We acknowledge financial support from the Title XII Bean/Cowpea CRSP (AID contract no. DNA-1310-GSS-6008-00). We also appreciate assistance of technicians Lisa Sutton and James Reiser. The cost of publishing this paper was defrayed in part by the payment of page charges. Under postal regulations, this paper therefore must be hereby marked advertisement solely to indicate this fact.

${ }^{1}$ Current address: Dept. of Horticulture, Univ. of Wisconsin, Madison, WI 53706. use of resistant cultivars (Sanders and Schwartz, 1980).

Germplasm with CBB (Coyne and Schuster, 1983) and WB resistance (Pastor-Corrales and Abawi, 1988) has been identified in common bean. For resistance to $\mathrm{CBB}$, quantitative patterns of inheritance, differential leaf and pod reactions, and low heritability have been reported (Arnaud-Santana et al., 1994; Coyne and Schuster, 1974; Valladares-Sanchez et al., 1979). Deakin and Dukes (1975) found that resistance to WB was highly heritable and controlled by a few dominant genes. However, low heritability estimates were found by Silva and Hartmann (1982). In addition to physiological resistance, plant architecture may also be important for the determination of disease severity (Beebe and PastorCorrales, 1991; Coyne, 1980)

Complex inheritance and low heritabilities make the transfer of quantitatively inherited disease resistance genes into elite cultivars difficult. Breeding problems associated with quantitatively inherited disease resistance are compounded by the need to breed resistance to multiple diseases into the same cultivar. In addition, 
it may be desirable to pyramid resistance genes to the same pathogen into a single cultivar to achieve more stable resistance (Nelson, 1978; Schafer and Roelfs, 1985). The development of molecular marker linkage maps makes it possible to locate and manipulate individual genetic factors associated with complex traits (Edwards et al., 1987; Tanksley et al., 1993). Such maps may be useful for studying the genetics of resistance to $\mathrm{CBB}$ and $\mathrm{WB}$ and quantitatively inherited plant architectural traits. In addition, the use of molecular markers for marker assisted selection (MAS) can contribute to breeding for disease resistance when the identification of resistant genotypes is difficult or when it is desirable to pyramid resistance genes from different sources into a single cultivar (Melchinger, 1990). However, linkages are needed to $\mathrm{CBB}$ and WB resistance genes before MAS will be useful for these traits. Except for one study (Nodari et al., 1993b) in which the genomic locations were identified for QTL associated with CBB resistance, there have been no attempts to identify the genomic locations for genes controlling CBB resistance, $\mathrm{WB}$ resistance, or plant architectural traits in common bean.

The objectives of the research reported here were to 1) identify markers linked to QTL conferring CBB resistance in different plant organs, 2) identify markers linked to QTL controlling expression of WB resistance, 3) identify QTL associated with quantitatively inherited plant architectural traits, 4) identify markers linked to a gene for rust resistance, and 5) describe linkage relationships among genes affecting expression of each of these traits, for a recombinant inbred population of common bean.

\section{Materials and Methods}

Mapping population. One hundred twenty-eight $\mathrm{F}_{6} \mathrm{RI}$ (recombinant inbred) lines from the cross BAC $6 \times$ HT 7719 were developed by single-seed descent (SSD). Accession HT 7719 is a black-seeded breeding line susceptible to $\mathrm{CBB}$, resistant to $\mathrm{WB}$ (Rhizoctonia solani, AG-1-1B), and susceptible to rust (race D85C-1, Dominican Republic). HT 7719 has an upright plant structure (Type II) and low branch density. BAC 6 is resistant to $\mathrm{CBB}$, susceptible to $\mathrm{WB}$, and resistant to rust. It has a prostrate plant type (Type III) and high branch density. HT 7719 and BAC 6 are unrelated by pedigree but, based on phenotypic characteristics and molecular marker genotypes (data not shown), both are members of race mesoamerica.

Phenotypic data. In 1991, the $128 \mathrm{~F}_{6} \mathrm{RI}$ lines and their parents were grown in a WB nursery, in Buena Vista, San Juan de la Maguana, Dominican Republic (Arnaud-Santana, 1992). The region is located at about $420 \mathrm{~m}$ above sea level with a mean annual temperature of $25^{\circ} \mathrm{C}$, mean seasonal rainfall of 125 to $150 \mathrm{~mm}$, and high relative humidity $(>80 \%)$ during the bean growing season. The lines and parents were arranged in a randomized completeblock design with three replications. Single-row plots were used for each entry. The plants were infected by WB under natural conditions in the WB nursery. The lines were rated on a scale from 1 (no symptoms on plants) to 9 ( $80 \%$ or more of the row or line showing the disease symptoms). However, only the odd numbers were used to rate disease symptoms. WB evaluations were repeated in 1992 using $128 \mathrm{~F}_{7} \mathrm{RI}$ lines derived by SSD from the $\mathrm{F}_{6}$ lines used in the $1991 \mathrm{WB}$ evaluation.

For each $\mathrm{F}_{6}$ line evaluated for WB resistance in 1991, leaves with stems attached were removed, rooted in a greenhouse, and inoculated with CBB strain Epif-IV in two replicates (three plants per replicate) (Arnaud-Santana, 1992). For this experiment, disease screening methods and disease rating scales were as described by Arnaud-Santana et al. (1994).
Phenotypic data on plant uprightness (PU) and branch density (BD) were recorded using the $128 \mathrm{~F}_{6} \mathrm{RI}$ lines and their parents in the WB nursery as described by Arnaud-Santana (1992). Plant uprightness varied from 1 (upright) to 9 (prostrate) and branch density varied from 1 (low branch density) to 9 (high branch density).

In 1994, the $128 \mathrm{~F}_{8}$ RI lines selfed from each line of the $\mathrm{F}_{6}$ population and their parents were grown in the greenhouse in Lincoln, Neb., and inoculated with CBB strain EK-11 (Ariyarathne, 1994). Inoculation and disease rating for leaves, pods, and seeds were performed as described by Arnaud-Santana et al. (1994). A randomized complete-block design with two replications (three plants per replicate) was used in 1994. Greenhouse temperatures ranged between $27 \pm 2{ }^{\circ} \mathrm{C}$ and $22 \pm 2{ }^{\circ} \mathrm{C}$ day/night, and the average natural day length ranged from 11 to $12 \mathrm{~h}$ during the period January to March 1994.

For rust evaluations, each $\mathrm{F}_{7} \mathrm{RI}$ line was grown and inoculated on the primary leaves 7 days after planting using the rust race D85C-1 in the greenhouse in Lincoln, in 1993. The RI lines were replicated three times in a randomized complete-block design. Visual ratings of rust sporulation on the primary leaves were recorded for the $128 \mathrm{~F}_{7} \mathrm{RI}$ lines and their parents as described by Bokosi et al. (1995).

Distributions of RI line means for $\mathrm{CBB}$ resistance measured for strain EK-11 in first trifoliolate leaves, later-developed trifoliolate leaves, and pods and distributions of PU and BD deviated significantly from normal (Fig. 1). Transformations to achieve normality were attempted but were not successful. Untransformed data was used in the analysis. Distributions for WB, resistance for $\mathrm{CBB}$ strain Epif-IV, and resistance to CBB strain EK-11 measured for seeds did not deviate significantly from normal.

Molecular marker data. RAPD (Williams et al., 1990) genetic markers were generated as follows. Total genomic DNA was prepared from lyophilized fully expanded trifoliolate leaves of the above $128 \mathrm{~F}_{6} \mathrm{RI}$ lines and the two parental lines using the method previously described by Skroch and Nienhuis (1995). Polymerase chain reactions were performed in an air thermalcycler (model 1605; Idaho Technology, Idaho Falls) in thin-walled glass capillary tubes as described by Skroch and Nienhuis (1995).

The 10 base primers used for the RAPD reactions were obtained from Operon Technologies (Alameda, Calif.) and the Univ. of British Columbia (Vancouver). The approximate length in base pairs was determined by comparing each RAPD marker with size markers from a 100-base pair ladder (Gibco BRL). Based on the migration distance of RAPD markers and size markers, the size of each marker was determined to the nearest 50 base pairs. Each RAPD was then named by the letter identifying the Operon kit and primer number (for their Operon origin) and the approximate length of the marker. Similarly, RAPD markers generated using British Columbia primers were designated by a BC prefix followed by the primer number (for their British Columbia kit origin) and the size of the marker. This method was adequate to unambiguously name all markers.

Linkage map construction. The segregation analysis of 84 RAPD markers and the rust resistance locus was performed on the data for $128 \mathrm{RI}$ lines using MAPMAKER Macintosh version 2.0 (Lander et al., 1987). The logarithm of odds (LOD) score of 3.0 was used as a linkage threshold with 0.3 as the maximum recombination fraction for linkage groups. Map distances (cM) were estimated using recombination fractions and Kosambi's mapping function (Kosambi, 1944) between ordered marker loci. Segregation at each marker locus was checked for deviation from the expected 1:1 ratio in $\mathrm{F}_{6} \mathrm{RI}$ lines based on a chi-square goodness of 
fit test (Table 1). Subsequent to the initial map construction, 98 additional markers were evaluated in this population, but genome coverage was not improved significantly, so these additional markers were not used for QTL analysis.

Identification of QTL. For QTL detection, the data were analyzed based on single-factor ANOVA for each pairwise combination of quantitative traits and marker loci. F tests $(P<0.05)$ were used to determine if significant differences in trait expression were associated with differences in marker locus-genotypic classes (Edwards et al., 1987). For linked markers $(<50 \mathrm{cM})$, only the marker showing the most significant association was assumed to be linked to a QTL for the trait and only that marker was considered in the analysis and interpretation of the results. The method of interval mapping (Lander and Botstein, 1989) was also used for the localization of QTL and the estimation of their genetic effects. The LOD score for the QTL threshold was set at 2.0 based on theoretical considerations (Lander and Botstein, 1989). Only linkages of three or more markers were included in the interval mapping analysis. Stepwise multiple regression was performed using marker loci associated with individual QTL as independent variables to determine the best multilocus model and the percentage of the phenotypic variance explained (Paterson et al., 1991). Marker loci significant at $P=0.05$ were included in the final model. A relatively high $P$ value (0.05) was used for detecting individual QTL and for stepwise regression analysis with the understanding that this may increase the experimental Type I error rate. However, lower stringency of detection is recommended as a way to reduce the probability of committing Type II errors (Edwards et al., 1992). In addition, we report all QTL objectively in terms of their statistical significance ( $P$ value). This allowed us to derive as much information from our study as possible while remaining statistically responsible.

\section{Results and Discussion}

RAPD marker segregation. Primers were preselected based on polymorphism between the parents. For primers selected for this study, an average of 1.2 bands per primer were generated, resulting
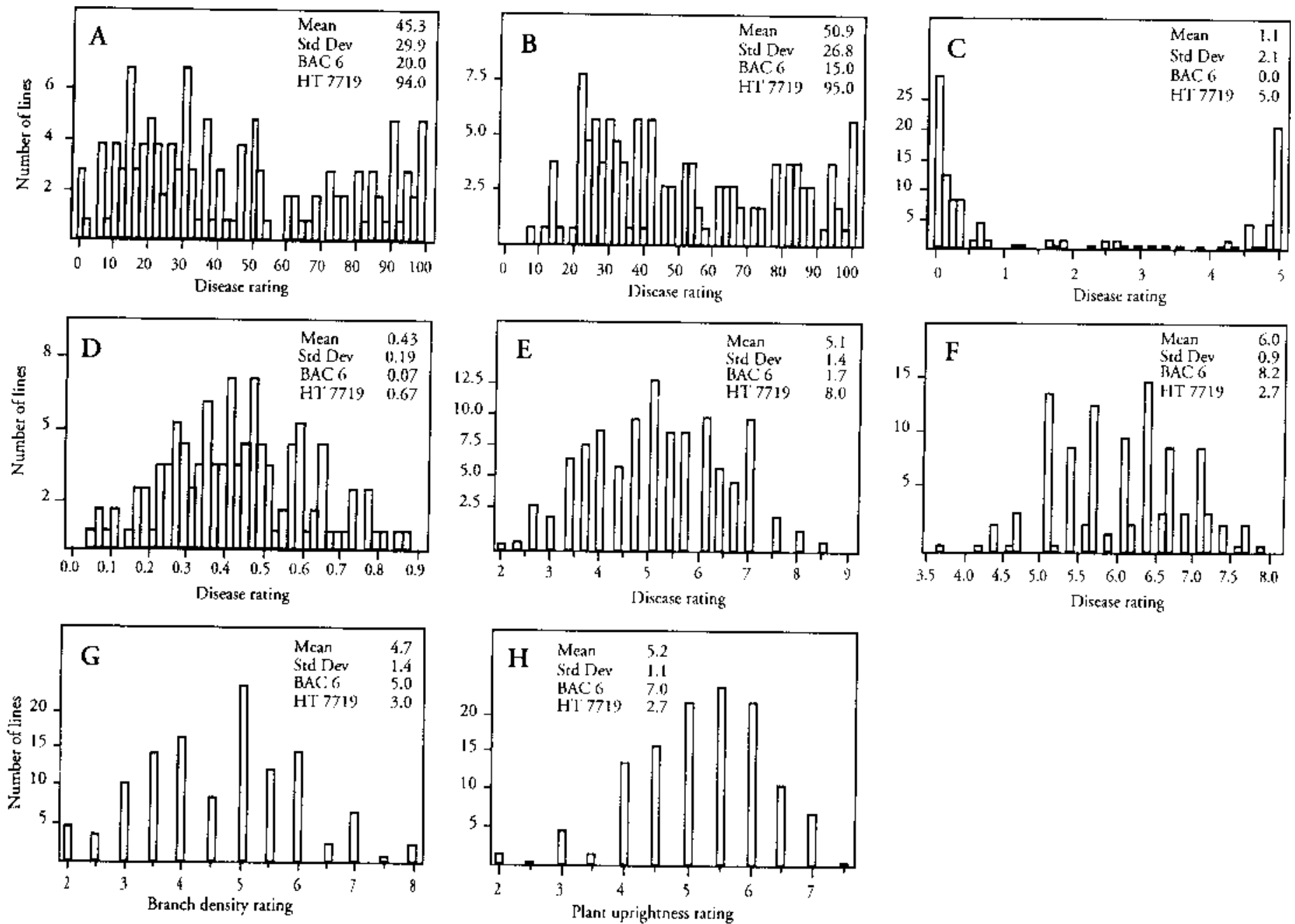

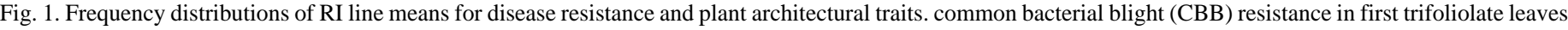

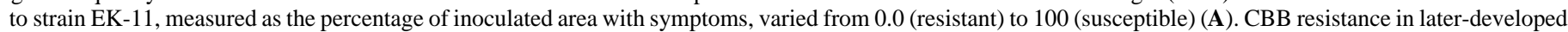

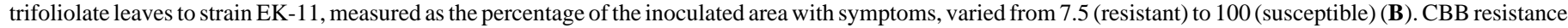

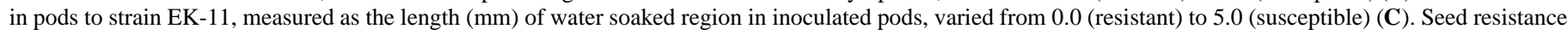

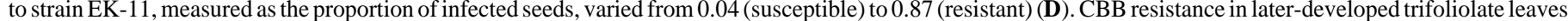

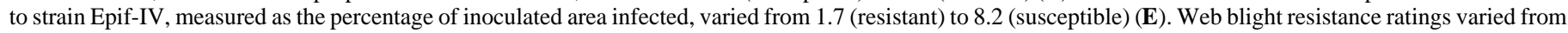

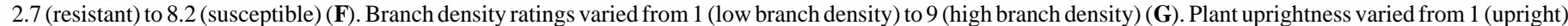
to 9 (prostrate) (H). CBB resistance in leaves, web blight resistance, branch density and plant uprightness evaluations were based on visual ratings. 
in the evaluation of 84 RAPD markers segregating in the population of 128 RI lines. Sixty-five (77\%) RAPD markers and the rust resistance locus, fit the expected 1:1 ratio in the RI population based on a chi-square goodness of fit test (Table 1). Markers in which segregation distortion was observed were distributed over six linkage groups, with ten favoring the BAC 6 allele and nine favoring the HT 7719 allele. Lower proportions (8\% and 9\%) of RFLP markers with segregation distortion have been observed in common bean $\mathrm{F}_{2}$ populations (Nodari et al., 1993a; Vallejos et al., 1992). The cause of the high percentage of segregation distortion in this $\mathrm{F}_{6} \mathrm{RI}$ mapping population is unknown. However, several factors could have contributed to this result including genetic drift during inbreeding and natural selection, which may have occurred during fertilization, gametogenesis, seed development, and plant growth.

Linkage map construction. Seventy-five markers were mapped to eight linkage groups with nine unassigned markers (Table 1, Fig. 2 ). The haploid chromosome number of Phaseolus vulgaris is 11 $(2 n=22)$; thus, three more linkage groups remain to be detected. The average linkage distance between pairs of markers among all linkage groups was $7.4 \mathrm{cM}$ (Table 1 ). Only three intervals located in linkage groups 2, 3, and 4 were larger than $20 \mathrm{cM}(27.5,26$, and $26.7 \mathrm{cM}$, respectively), with the LOD score for these intervals above the threshold of 3.0 (Fig. 2). Most of the intervals (>69\%) were smaller than $10 \mathrm{cM}$. Alternate RAPD alleles showing a codominant segregation pattern were amplified for marker loci

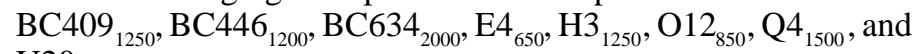
$\mathrm{U}^{2} \mathrm{O}_{1050}{ }^{\circ}$

The linkage map reported here spans $545 \mathrm{cM}$ in contrast to the 871 and $963 \mathrm{cM}$ for published maps of common bean constructed using RFLP markers as reported by Nodari et al. (1993a) and Vallejos et al. (1992), respectively. In addition to the 84 RAPD markers included in this report, about 100 additional RAPD markers have been mapped in the BAC $6 \times$ HT 7719 population without increasing the genome coverage significantly (not shown). The failure to achieve better genome coverage suggests that researchers intending to do genome analysis should use wider crosses. In fact, the populations used for construction of RFLP maps in common bean (described above) were developed from intergene pool crosses with that specific objective. However, the BAC $6 \times$ HT 7719 population was originally developed in the context of a dry bean breeding program and, therefore, was designed to achieve breeding objectives rather then the objectives of genomic research. Although this made the detection of marker polymorphisms more difficult, the information obtained through the use of a typical breeding population may ultimately be more directly applicable to plant breeding problems. Furthermore, the difficulty of linkage map construction in such populations makes the partial linkage map constructed in this study valuable as a starting point for future mapping and gene tagging experiments.

Location of rust resistance. A bimodal distribution pattern was observed for primary leaf reaction to rust. A good fit to a 1:1 ratio for segregation of rust resistance and susceptibility was detected in $\mathrm{F}_{7} \mathrm{RI}$ lines. The rust gene controlling small pustule resistance on primary leaves was mapped to a location in linkage group 1 flanked on one side $12.5 \mathrm{cM}$ from marker AJ16 ${ }_{250}$ and on the other side 14.6 cM from marker H19 ${ }_{1050}$ (Fig. 2). RAPD molecular markers have been used to identify markers linked to four rust resistance genes in common bean (Steadman et al., 1995). However, this is the first report on the mapping of a small pustule rust resistance gene. The small pustule rust resistance gene mapped in this study may be the same gene (URPR1) described by Webster and Ainsworth (1988). However, an allelic test is needed to verify the identity of the gene mapped here as URPR1.

Miklas et al. (1993) described RAPD markers tightly linked to a rust resistance gene and suggested the use of RAPD markers for pyramiding different rust resistance genes in common bean. Although not tightly linked, simultaneous selection for the flanking markers $\mathrm{H} 19_{1050}$ and $\mathrm{AJ} 16_{250}$ described here could be useful for marker assisted selection (MAS). Segregation data indicated the proportion of recombinants was 0.20 for the rust gene and $\mathrm{H} 19_{1050}$, and 0.22 for the rust gene and $\mathrm{AJ} 16_{250}$. Assuming no interference, the expected proportion of double recombinants, for this interval, is about 0.04 in the $\mathrm{F}_{7}$ and 0.01 in the $\mathrm{F}_{2}$ generation. Thus, assuming no interference, simultaneous selection for these two markers in an $\mathrm{F}_{2}$ population should also result in selection for the rust gene about $99 \%$ of the time. However, more closely linked markers should be sought to reduce linkage drag associated with the size of the interval and to improve the potential efficiency of MAS based on individual markers.

$Q T L$ for $C B B$ resistance. For CBB strain EK-11, no QTL were detected using interval mapping for $\mathrm{CBB}$ resistance in first or later developed trifoliolate leaves. However, five markers were significantly associated with resistance to $\mathrm{CBB}$ in first trifoliolate leaves based on single-factor ANOVA, including two, $\mathrm{AD}_{450}$ and Q1 ${ }_{600}$, for which the resistant allele was contributed by the susceptible parent. Three of these five were included in the final multilocus model indicated by the stepwise regression results and accounted

Table 1. Description of the genetic linkage map consisting of 79 mapped RAPD markers segregating among recombinant inbred lines derived from the common bean cross BAC 6 × HT 7719.

\begin{tabular}{lcccc}
\hline \hline $\begin{array}{l}\text { Linkage } \\
\text { group }\end{array}$ & No. & $\begin{array}{c}\text { Map } \\
\text { distance }\end{array}$ & Spacing $^{\mathrm{z}}$ & $\begin{array}{c}\text { Segregation } \\
\text { distortion }^{\mathrm{x}}\end{array}$ \\
\hline 1 & 20 & 153 & 7.7 & 2 \\
2 & 14 & 132 & 9.4 & 2 \\
3 & 7 & 77 & 11 & 5 \\
4 & 4 & 45 & 11.3 & 0 \\
5 & 8 & 40 & 5 & 8 \\
6 & 10 & 36 & 3.6 & 1 \\
7 & 5 & 35 & 7 & 0 \\
8 & 7 & 27 & 3.9 & 1 \\
Unassigned markers & 9 & & & 0 \\
Total & 84 & 545 & & 19 \\
\hline
\end{tabular}

${ }^{\mathrm{z}}$ Map distance in cM based on the Kosambi mapping function.

y Mean distance $(\mathrm{cM})$ between adjacent markers.

${ }^{\mathrm{x}}$ Number of markers deviating significantly from the expected $1: 1$ segregation $(P<0.05)$. 
for $21 \%$ of the phenotypic variation for the trait. Marker BC409 ${ }_{1250}$, which was unlinked, accounted for $12 \%$, marker $\mathrm{Z}_{600}$, which was linked to only one other marker, accounted for $6 \%$, and marker W11 1550 accounted for $3 \%$ of the variation for this trait (Table 2). Three unmapped and four mapped markers were found to be significantly associated with resistance in later developed trifoliolate leaves by single-factor ANOVA, including marker Q1 ${ }_{600}$, which was also significantly associated $(P<0.05)$ with resistance in first trifoliolate leaves and for which the resistant allele was contributed by the susceptible parent. Four of the markers significant by single-factor ANOVA, including the three unmapped markers, were significant in the multiple regression analysis accounting for $29 \%$ of the phenotypic variation for this trait. Marker BC409 ${ }_{1250}$ accounted for $13 \%, \mathrm{G} 17_{1400}$ accounted for $7 \%$,

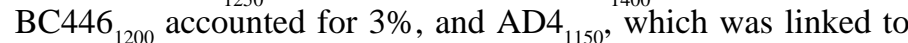
$\mathrm{Z}_{600}(14.3 \mathrm{cM})$, accounted for $6 \%$ of the variation for this trait (Table 2).

For resistance in later-developed trifoliolate leaves to $\mathrm{CBB}$ strain Epif-IV, one significant region was identified by interval mapping (Table 2, Fig. 2), while seven marker locus-trait associations were identified by single-factor ANOVA. Six loci were significant in the multiple regression analysis with a cumulative $R^{2}$ of $28 \%$. Marker U16 600 , which mapped nearest to the most likely position of the QTL identified by interval mapping, accounted for $10 \%$ of the variation for this trait (Table 2). In addition, markers $\mathrm{U} 8_{1100}, \mathrm{BC} 409_{1250}, \mathrm{AD}_{1150}, \mathrm{C} 1_{1550}$, and $\mathrm{F} 13_{300}$ accounted for $5 \%$, $4 \%, 3 \%, 3 \%$, and $3 \%$ of the variation, respectively (Table 2). For three of these markers associated with small effects, $\mathrm{U} 8_{1100}, \mathrm{C} 1_{1550}$, and $\mathrm{F} 13_{300}$, the resistant allele was contributed by the susceptible parent.

For pod resistance to strain EK-11, only one QTL was detected by interval mapping, associated with the interval, $\mathrm{K} 19_{450}-\mathrm{I} 7_{700}$, in linkage group 5 (Fig. 2). Five significant markers were found by single-factor ANOVA including two, $\mathrm{AD}_{450}$ and $\mathrm{W}_{300}$, for which the resistant allele was contributed by the susceptible parent However only two of these five were retained in the multiple regression model: $\mathrm{K} 19_{450}$, which mapped nearest to the most probable location of the QTL identified through interval mapping, and BC409 ${ }_{1250}$ which was unmapped. Markers K19 ${ }_{450}$ and BC409 ${ }_{1250}$ accounted for 7 and 17 percent of the phenotypic variation, respectively (Table 2), based on the multiple regression analysis.

For seed resistance, interval mapping detected no intervals with

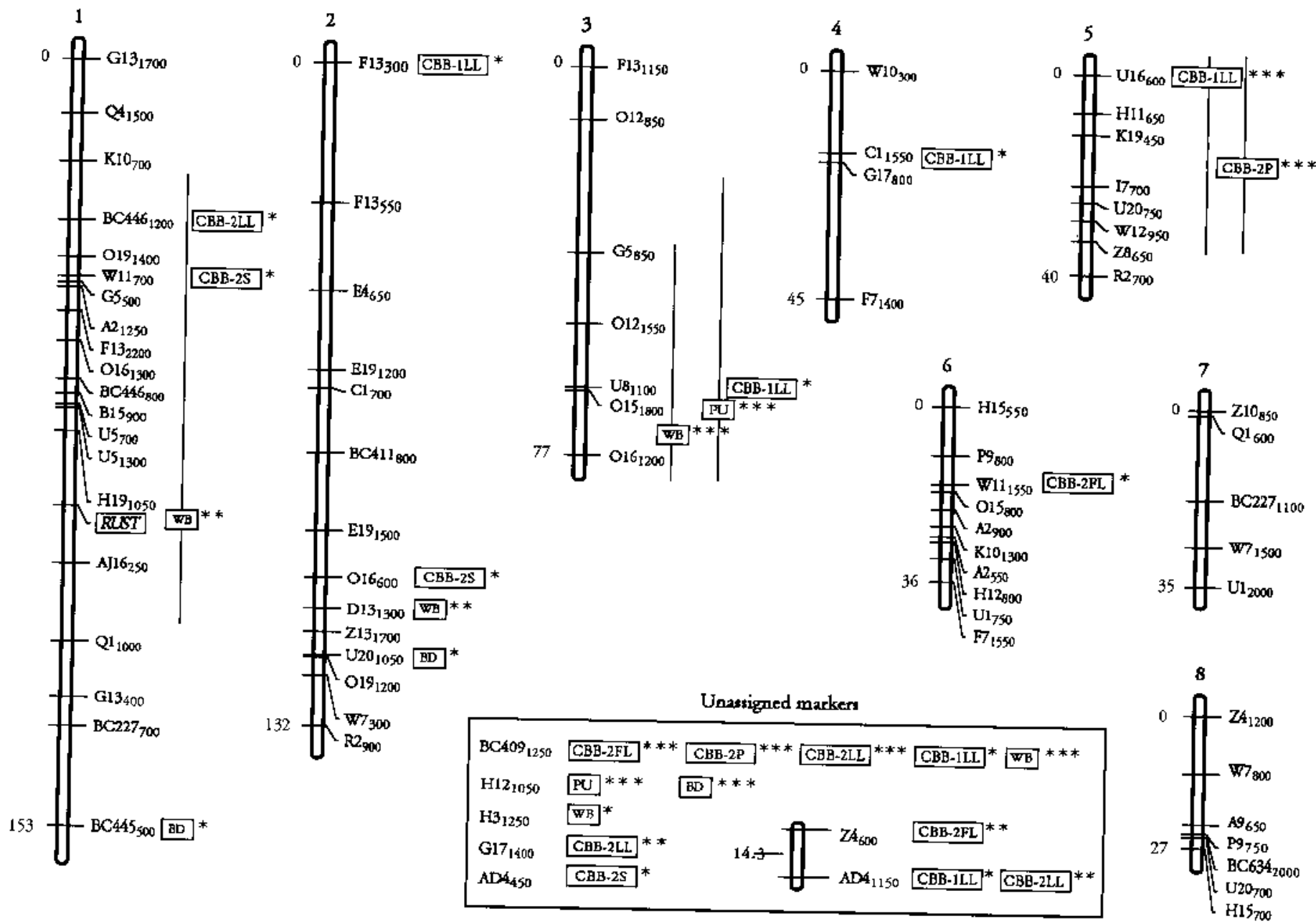

Fig. 2. Linkage map constructed using RAPD markers. The gene and marker names are given on the right and the length in cM is indicated on the left of each linkage group. Markers significant $(P<0.05)$ in a multi-locus stepwise regression analysis, using marker loci significantly associated with traits by single-factor ANOVA as independent variables, are indicated by boxes for 1) resistance to common bacterial blight (CBB) strain EK-11 in first trifoliolate leaves (CBB-2FL), later-developed trifoliolate leaves (CBB-2LL), seeds (CBB-2S), and pods (CBB-2P); 2) resistance to CBB strain Epif-IV in later-developed trifoliolate leaves (CBB-1LL); 3) resistance to web blight (WB); 4) branch density (BD), and 5) plant uprightness (PU). ******* Significant at $P<0.05,0.01$, or 0.001 , respectively, for each marker locus-trait association. For each QTL detected by interval mapping with an LOD $>2.0$, the most likely position of the QTL is indicated by boxes and lines emanating from the boxes indicate two LOD confidence intervals. Unassigned markers that were significantly associated with trait variation are also identified. 
an LOD above 2.0. However, three marker locus-trait associations were detected by single-factor ANOVA $(0.0166<P<0.0237)$ (Table 2). Due to the low LOD scores and low significance levels for the regression results these must be considered candidate marker locus-QTL associations, pending future confirmation. Markers $\mathrm{O} 16_{600}, \mathrm{AD}_{450}$, and $\mathrm{W} 11_{700}$ accounted for $5 \%, 5 \%$, and $4 \%$ of the variation for this trait, respectively (Table 2 ). These results are also interesting because, at all three loci, the resistant allele was contributed by the susceptible parent, HT 7719 .

Based on the number of resistant genotypes found in a population of inbred backcross lines, Eskridge and Coyne (1996) have recently estimated the number of genes controlling CBB resistance in our resistant parent, BAC 6, to be 2.6 (leaf) and 3.7 (pod) for CBB strain EK-11. The number of significant marker locus-QTL

Table 2. Summary of the single-factor ANOVA, interval mapping, and multiple regression analysis of molecular marker and phenotypic data for detection of QTL associated with resistance to common bacterial blight (CBB) in different plant organs and for different CBB strains in recombinant inbred lines derived from the common bean cross BAC 6 x HT 7719 .

\begin{tabular}{|c|c|c|c|c|c|c|c|}
\hline \multirow{2}{*}{$\begin{array}{l}\text { Plant } \\
\text { organ }\end{array}$} & \multirow[b]{2}{*}{ Location $^{\text {z }}$} & \multicolumn{2}{|c|}{$\begin{array}{l}\text { Single-factor } \\
\text { ANOVA }\end{array}$} & \multirow{2}{*}{$\begin{array}{c}\begin{array}{c}\text { Interval } \\
\text { mapping }\end{array} \\
\text { LOD }^{\mathrm{w}}\end{array}$} & \multicolumn{2}{|c|}{$\begin{array}{l}\text { Multiple } \\
\text { regression }\end{array}$} & \multirow{2}{*}{$\begin{array}{l}\text { Linkage } \\
\text { group }^{t}\end{array}$} \\
\hline & & $\overline{P>\mathrm{F}^{\mathrm{y}}}$ & $R^{2 \mathrm{x}}$ & & $P>\mathrm{F}^{v}$ & $R^{2 \mathrm{u}}$ & \\
\hline
\end{tabular}

Later-developed trifoliolate

$\begin{array}{ll}\mathrm{U} 16_{600}-\mathrm{H} 11_{650} & 0.0006 \\ \mathrm{U} 8_{1100} & 0.0296 \\ \mathrm{BC} 409_{1250} & 0.0110 \\ \mathrm{AD} 4_{1150} & 0.0274 \\ \mathrm{C} 1_{1550} & 0.0215 \\ \mathrm{~F} 13_{300} & 0.0406 \\ \mathrm{~W}_{800} & 0.0192 \\ \text { Cumulative } R^{2} & \end{array}$

$0.72 \quad 0008$
0.0127
0.0200
0.0259
0.0404
0.0367
0.1692

$F_{8}$ RI lines inoculated with CBB strain EK-11

First trifoliolate

$\begin{array}{ll}\mathrm{BC} 409_{1250} & 0.0001 \\ \mathrm{Z}_{600} & 0.0086 \\ \mathrm{AD}_{450} & 0.0195 \\ \mathrm{Q}_{600} & 0.0317 \\ \mathrm{~W}_{11} 1_{1550} & 0.0300 \\ \text { Cumulative } R^{2} & \end{array}$

$\begin{array}{ll}11 & 0.0001 \\ 6 & 0.0026 \\ 4 & 0.1566 \\ 4 & 0.0545 \\ 4 & 0.0424\end{array}$

Later-developed trifoliolate

$\begin{array}{lll}\text { BC409 } & & \\ \mathrm{G}_{1250} & 0.0001 & 13 \\ \mathrm{AD}_{1100} & 0.0012 & 7 \\ \mathrm{BC}_{145} & 0.0032 & \\ \mathrm{~K}_{1200} & 0.0250 & 4 \\ \mathrm{Q}_{450} & 0.01527 & 3 \\ \mathrm{~W}_{800} & 0.02886 & 4 \\ \text { Cumulative } R^{2} & 0.03318 & \end{array}$

Pod

$\begin{array}{lll}\mathrm{BC} 409_{1250} & 0.0000 & 17 \\ \mathrm{~K}_{1} 9_{450} \mathrm{II} 7_{700} & 0.0001 & 1 \\ \mathrm{AD}_{450} & 0.0136 & \\ \mathrm{~W} 7_{300} & 0.0245 & \\ \mathrm{~W} 7_{800} & 0.0400 & \\ \text { Cumulative } R^{2} & & \end{array}$

Seed

\begin{tabular}{|c|c|c|c|c|c|}
\hline $\mathrm{O} 16_{600}$ & 0.0166 & 5 & 0.0125 & 5 & 2 \\
\hline $\mathrm{AD}_{450}$ & 0.0181 & 5 & 0.0146 & 5 & UM \\
\hline $\mathrm{W} 11_{700}^{450}$ & 0.0237 & 4 & 0.0206 & 4 & 1 \\
\hline Cumulative $R^{2}$ & & & & 14 & \\
\hline
\end{tabular}

${ }^{\mathrm{z}}$ Marker or interval significantly associated with trait variation.

${ }^{\mathrm{y}}$ Significance levels determined for $\mathrm{F}$ tests based on the single-factor ANOVA for each pairwise comparison of a quantitative trait and marker locus. xPercentage of phenotypic variation explained by the marker locus based on single-factor ANOVA analysis of marker-trait associations.

wLOD value at most likely QTL location as determined by Mapmaker QTL.

${ }^{v}$ Significance levels determined for $\mathrm{F}$ tests based on multiple regression analysis of marker locus-trait associations for markers found to be significant by single-factor ANOVA $(P<0.05)$.

uPercentage of phenotypic variation explained, for significant $(P<0.05)$ marker locus-trait associations, based on multiple regression analysis. tLinkage group membership of markers and intervals significantly associated with trait variation for linkage groups as defined in Fig. 1 (UM = unassigned marker). 
associations detected in this study by single-factor ANOVA was greater than this for both traits but the results of the multiple regression analysis indicated only three, four, and two significant loci for first trifoliolate leaves, later developed trifoliolate leaves and pods, respectively. Thus, despite incomplete genome coverage and association of many effects with unmapped markers, the number of significant marker locus-trait associations for CBB resistance in leaves and pods appears to be in general agreement with the results of Eskridge and Coyne (1996). However, the QTL detected for CBB resistance in this study accounted for only $14 \%$ to $29 \%$ of the phenotypic variation, depending on the plant organ and bacterial strain (Table 2). This inconsistency may be partially or wholly explained by the fact that most of the significant effects in the multiple regression models were associated with unmapped markers. Loose linkage between unmapped markers and associated QTL may have resulted in an underestimation of the effects of these QTL. There is also the possibility that inadequate genome coverage resulted in failure to detect some QTL in unmapped regions. Note that only two markers remained in the multiple regression model for pod resistance compared to the 3.7 genes estimated by Eskridge and Coyne (1996) for this trait.

Nodari et al. (1993b) were able to explain about $75 \%$ of the phenotypic variation for CBB resistance in leaves with four QTL in an $\mathrm{F}_{2}$ population segregating from the cross BAT $93 \times$ Jalo EEP 558. However, the total $R^{2}$ values reported by Nodari et al. (1993b) were based on the sum of individual $R^{2}$ values rather than stepwise regression analysis, which tends to lower overall $R^{2}$ values. The CBB strain used in the earlier study by Nodari et al. (1993b) was W18, different from the EK-11 and Epif-IV strains used in this study. In addition, a different source of resistance was used. The use of different sources of resistance and different pathogen strains suggests the possibility that different genes for $\mathrm{CBB}$ resistance are segregating in the two populations. The uniqueness of QTL associated with resistance in the two studies could be determined through the comparison of the genome locations for QTL detected, perhaps through linkage map integration.

Relationships among $Q T L$ for $C B B$ resistance. Two unmapped markers and three intervals in linkage groups 2, 5, and 8 accounted for 18 of the 27 significant associations detected by single-factor ANOVA for five traits measured for CBB strains EK-11 and EpifIV (Tables 2 and 3). Significant associations of different CBB traits with the same or closely linked marker loci are consistent with high phenotypic correlations measured for these traits (Table 4). Four markers or genomic regions found to be significantly associated with resistance to CBB strain Epif-IV were also found to be significantly associated with resistance in leaves or pods for strain EK-11 (Tables 2 and 3). Although additional work is needed to confirm these associations and to determine to what extent the results are due to unlikely chance events, linkage, or pleiotropy, the result suggests a pleiotropic effect at least some of these loci. In addition, the consistency of significant associations across plant organs and bacterial strains strengthens evidence for marker locus-QTL linkages effecting common bacterial blight resistance. The CBB strains Epif-IV and EK-11 were chosen to represent two geographical regions (temperate and tropical) corresponding to the Nebraska and Dominican Republic bean production environments. The finding that similar genomic regions are effecting resistance to different pathogen strains indicates that these genes may be very useful for breeding cultivars with a broad range of resistance.

The existence of unique $\mathrm{CBB}$ resistance genes controlling $\mathrm{CBB}$ resistance in different plant organs has been suggested (ValladaresSanchez et al., 1979). However, in contrast to the low and nonsignificant correlation of $\mathrm{CBB}$ resistance in leaves with $\mathrm{CBB}$ resistance in pods reported by Valladares-Sanchez et al. (1979), high phenotypic correlations are reported here (Table 4). In addition, all markers found to be significantly associated with $\mathrm{CBB}$ resistance in pods were either also significantly associated with resistance in leaves or linked to a marker that was significantly associated with resistance in leaves (Table 2). Thus, the results of the QTL analysis are consistent with the phenotypic correlations and indicate that, for progeny segregating from the cross BAC 6 x HT 7719, only genes with minor effects would be acting independently in pods and leaves. However, one marker, $\mathrm{G} 17_{1400}$, was highly significant $(P=0.0012)$ for resistance measured for later developed trifoliolate leaves only (Table 2). This association is interesting because it suggests the possibility of a plant organ specific QTL for CBB resistance as well as resistance genes that are related to the developmental stage of the plant.

The observation that all candidate marker locus-QTL associations detected for resistance to seed infection were contributed by the susceptible parent may indicate unique genes for resistance to seed infection, contributed by the resistant parent, that exist in regions of the genome that were not mapped in our study. However, on a practical level, resistance in leaves and pods will likely prevent seed infection so that unique genes for seed resistance may not be necessary for breeding resistant cultivars. The high phenotypic correlation for pod and leaf resistance also indicates that selection based on leaf resistance should be effective in achieving resistance in pods and indirectly, seeds.

QTL analyses of WB resistance. Means for WB resistance varied from 7.83 (susceptible) to 3.67 (resistant) and were nor-

Table 3. Summary of marker loci or regions within linkage groups for which significant marker locus-trait associations were found for three or more of six disease resistance traits.

\begin{tabular}{|c|c|c|c|c|c|c|}
\hline \multirow[b]{2}{*}{ Marker or marker linkage } & \multicolumn{6}{|c|}{ Disease resistance trait ${ }^{2}$} \\
\hline & LDL1 & FDL2 & LDL2 & PD2 & SD2 & WB \\
\hline BC409 & $\mathrm{X}^{* \mathrm{y}}$ & $\mathrm{X}^{* * *}$ & $\mathrm{X}^{* * * *}$ & $\mathrm{X}^{* * * *}$ & & $\mathrm{X}^{* *}$ \\
\hline $\mathrm{AD}_{450}$ & & $\mathrm{X}^{*}$ & & $\mathrm{X}^{*}$ & $\mathrm{X}^{*}$ & \\
\hline $\mathrm{AD} 4_{1150}^{430}-\mathrm{Z} 4_{600}$ & $\mathrm{X}^{*}$ & $\mathrm{X}^{* *}$ & $\mathrm{X}^{* *}$ & & & \\
\hline $\mathrm{W} 7_{800}^{1150}$ & $\mathrm{X}^{*}$ & & $\mathrm{X}^{*}$ & $\mathrm{X}^{*}$ & & \\
\hline $\mathrm{U} 16_{600}-\mathrm{K} 19_{450}-\mathrm{I} 7_{700}$ & $\mathrm{X}^{* * *}$ & & $\mathrm{X}^{*}$ & $\mathrm{X}^{* * * *}$ & & $\mathrm{X}^{*}$ \\
\hline $\mathrm{O} 16_{600}-\mathrm{W} 7_{300}$ & & & & $\mathrm{X}^{*}$ & $\mathrm{X}^{*}$ & $\mathrm{X}^{* *}$ \\
\hline
\end{tabular}

${ }^{\mathrm{z}}$ Common bacterial blight (CBB) resistance measured for CBB strain Epif-IV in later developed trifoliolate leaves (LDL1), for CBB strain EK-11 in first trifoliolate leaves (FDL2), later-developed trifoliolate leaves (LDL2), pods (PD2), and seeds (SD2) and resistance to web blight (WB).

${ }^{\mathrm{y}} \mathrm{X}=\mathrm{a}$ significant marker locus-trait association..

${ }^{*, * *, * * *}$ Significant at $P=0.05,0.01$, or 0.001 , respectively. 
Table 4. Phenotypic correlations for resistance to common bacterial blight (CBB) strains Epif-IV and EK-11, web blight (WB) resistance, and plant architectural (PA) traits for 128 recombinant inbred lines derived from the cross BAC $6 \times$ HT 7719.

\begin{tabular}{|c|c|c|c|c|c|c|c|c|}
\hline \multirow[b]{2}{*}{ Trait } & \multirow{2}{*}{$\begin{array}{l}\text { CBB strain } \\
\text { Epif-IV }\end{array}$} & \multicolumn{4}{|c|}{ CBB strain EK-11 } & \multirow[b]{2}{*}{ WB } & \multicolumn{2}{|c|}{ PA } \\
\hline & & FT & LT & PD & SD & & $\mathrm{BD}$ & PU \\
\hline \multicolumn{9}{|l|}{$\overline{\text { CBB strain Epif-IV }}$} \\
\hline Later-developed trifoliolate (LT) & 1.00 & $0.57^{* *}$ & $0.53^{* *}$ & $0.57^{* *}$ & 0.10 & -0.13 & -0.00 & 0.05 \\
\hline \multicolumn{9}{|l|}{ CBB strain EK-11 } \\
\hline First trifoliolate (FT) & & 1.00 & $0.77^{* *}$ & $0.82^{* *}$ & $0.26^{* *}$ & -0.16 & -0.03 & -0.09 \\
\hline Later-developed trifoliolate (LT) & & & 1.00 & $0.78^{* *}$ & $0.21^{*}$ & -0.15 & -0.17 & -0.15 \\
\hline Pod (PD) & & & & 1.00 & $0.25^{* *}$ & $-0.24^{* *}$ & -0.06 & -0.13 \\
\hline Seed (SD) & & & & & 1.00 & -0.08 & -0.02 & 0.01 \\
\hline WB & & & & & & 1.00 & 0.02 & 0.08 \\
\hline \multicolumn{9}{|l|}{ PA } \\
\hline Branch density (BD) & & & & & & & 1.00 & $0.50^{* *}$ \\
\hline Plant uprightness (PU) & & & & & & & & 1.00 \\
\hline
\end{tabular}

**** Significant at $P=0.05$ or 0.01 , respectively.

mally distributed. No family was as susceptible as the most susceptible parent (BAC 6; WB rating $=8.2$ ) or as resistant as the most resistant parent $(\mathrm{HT} 7719$; WB rating $=2.7$ ). The results of the QTL analysis here indicate that there are at least five independent genes controlling WB resistance segregating from the cross BAC 6 x HT 7719 (Table 5). Two putative QTL, located nearest markers $\mathrm{H} 19_{1050}$ and $\mathrm{O} 16_{1200}$, were identified by interval mapping and single-factor ANOVA and five additional marker locus-trait associations were detected based on single-factor ANOVA but not interval mapping. Five of these seven markers were significant in the multiple regression analysis accounting for $34 \%$ of the variation for the trait. Markers O16 ${ }_{1200}$ (linkage group 3), H19 ${ }_{1050}$ (linkage group 1), D13 ${ }_{1300}$ (linkage group 2) and unmapped markers BC409 ${ }_{1250}$ and $\mathrm{H} 3_{1250}$ accounted for $10 \%, 7 \%, 5 \%, 10 \%$, and $2 \%$ of the total phenotypic variance, respectively, based on the multiple regression analysis (Table 5). Marker D13 ${ }_{1300}$ was significantly associated with WB resistance by single factor ANOVA, however, the LOD score for interval mapping at this locus was only 1.82 , just below our significance threshold of 2.0. Surprisingly, for this locus, WB resistance was associated with the D13 ${ }_{1300}$ allele from BAC 6, the susceptible parent. For other QTL, WB resistance was associated with the allele from the resistant parent.

Marker D13 ${ }_{1300}$ mapped in the $17.0 \mathrm{cM}$ interval on linkage group 2 between markers $\mathrm{O}_{16}{ }_{600}$ and $\mathrm{W}_{300}$. Based on single-factor ANOVA, the two markers flanking this interval were significant for resistance to $\mathrm{CBB}$, and in both cases the resistant allele was contributed by HT 7719, the parent susceptible to CBB and resistant to WB. $\mathrm{O}^{1} 6_{600}$ was significantly associated with resistance in seeds $(P=0.0166)$ and $\mathrm{W}_{300}$ was significantly associated with resistance in pods $(P=0.0245)$. In fact, six of the seven significant makers for WB found by single-factor ANOVA mapped within $15.3 \mathrm{cM}$ of a locus found to be significantly associated with a resistance to another pathogen (Tables 2, 4, and 5; Fig. 2). Notable among these is the association of $\mathrm{WB}$ and $\mathrm{CBB}$ resistance with unmapped marker $\mathrm{BC} 409_{1250}$ and $\mathrm{WB}$ resistance with the rust locus mapped in linkage group 1. Additional research is needed to determine to what extent these interesting associations reflect chance events, linkage, or pleiotropy.

Table 5. Summary of the single-factor ANOVA, interval mapping, and multiple regression analysis of molecular marker and phenotypic data for detection of QTL associated with foliar resistance to web blight (WB) in recombinant inbred lines derived from the common bean cross BAC 6 x HT 7719.

\begin{tabular}{|c|c|c|c|c|c|c|}
\hline \multirow[b]{2}{*}{ Marker $^{2}$} & \multicolumn{2}{|c|}{$\begin{array}{l}\text { Single factor } \\
\text { ANOVA }\end{array}$} & \multirow{2}{*}{$\frac{\begin{array}{c}\text { Interval } \\
\text { mapping }\end{array}}{\text { LOD }^{\mathrm{w}}}$} & \multicolumn{2}{|c|}{$\begin{array}{l}\text { Multiple } \\
\text { regression }\end{array}$} & \multirow{2}{*}{$\begin{array}{r}\text { Linkage } \\
\text { group }^{t}\end{array}$} \\
\hline & $P>\mathrm{F}^{\mathrm{y}}$ & $R^{2 \mathrm{x}}$ & & $P>\mathrm{F}^{\mathrm{v}}$ & $R^{2 \mathrm{u}}$ & \\
\hline$\overline{\mathrm{O} 16_{1200}-\mathrm{U} 8_{1100}}$ & 0.0006 & 9 & 3.33 & 0.0004 & 10 & 3 \\
\hline BC $409_{1250}$ & 0.0018 & 8 & & 0.0002 & 10 & UM \\
\hline $\mathrm{H} 19_{1050}-\mathrm{AJ} 16_{250}$ & 0.0071 & 6 & 2.25 & 0.0016 & 7 & 1 \\
\hline D13 $3_{1300}$ & 0.0025 & 7 & & 0.0041 & 5 & 2 \\
\hline $\mathrm{H} 3_{1250}$ & 0.0036 & 7 & & 0.0468 & 2 & UM \\
\hline $\mathrm{H} 11_{650}$ & 0.0181 & 5 & & 0.1135 & --- & 5 \\
\hline $\mathrm{H} 15_{700}$ & 0.0127 & 5 & & --- & --- & 8 \\
\hline Cumulative $R^{2}$ & & & & & 34 & \\
\hline
\end{tabular}

${ }^{\mathrm{z}}$ Marker or interval significantly associated with trait variation.

${ }^{\mathrm{y}}$ Significance levels determined for $\mathrm{F}$ tests based on the single-factor ANOVA for each pairwise comparison of a quantitative trait and marker locus. xPercentage of phenotypic variation explained by the marker locus based on single-factor ANOVA analysis of marker-trait associations.

wLOD value at most likely QTL location as determined by Mapmaker QTL.

${ }^{v}$ Significance levels determined for $\mathrm{F}$ tests based on multiple regression analysis of marker-trait associations for markers found to be significant by single-factor ANOVA $(P<0.05)$.

uPercentage of phenotypic variation explained by each marker locus, for significant $(P<0.05)$ marker-trait associations, based on stepwise multiple regression analysis.

${ }^{\text {t}}$ Linkage group membership of markers and intervals significantly associated with trait variation for linkage groups as defined in Fig. 1 (UM = unassigned marker). 
QTL analyses of plant architectural traits. One marker associated with plant uprightness was detected using single-factor ANOVA and interval mapping, and one additional significant association was detected by single-factor ANOVA only (Table 6). Plant uprightness was significantly associated with marker U8 ${ }_{1100}$, which mapped nearest to the most probable location of the QTL indicated by interval mapping, in linkage group three and unmapped marker $\mathrm{H}_{12} 2_{1050}$. These two loci accounted for $8 \%$ and $16 \%$ of the phenotypic variation, respectively. BD was significantly associated with unassigned markers $\mathrm{H} 12_{1050}$ and $\mathrm{U} 20_{1050}$ and mapped marker $\mathrm{BC}_{4} 45_{500}$ by single-factor ANOVA but not interval mapping and accounted for $9 \%, 5 \%$, and $4 \%$ of the phenotypic variation for $\mathrm{BD}$, respectively, based on the multiple regression analysis (Table 6). For marker H12 ${ }_{1050}$, the HT 7719 allele was associated with low BD and an upright habit. This marker accounted for $16 \%$ and $9 \%$ of the phenotypic variation in PU and BD, respectively, consistent with the positive phenotypic correlation (0.50) between PU and BD ratings. Plants with upright architecture and low BD may develop a microclimate that has better air circulation and light penetration and, thus, may be less favorable for WB development as has been shown for white mold in dry bean (Schwartz and Steadman, 1989). The detection of linked QTLs for WB resistance and PU in this study suggest that WB resistance in common bean may be partly explained by disease avoidance due to plant uprightness.

Impact of significance thresholds, analysis methods and data normality. For six disease resistance traits and two plant architectural traits a total of 39 significant marker locus-trait associations were found (Tables 2, 5, and 6). Twenty-two of these were moderately significant $(0.01<P<0.05)$, nine were significant at intermediate levels $(0.001<P<0.01)$, and eight were highly significant with significance probabilities $<0.001$, based on singlefactor ANOVA. Due to the number of traits measured and the number of markers tested it is almost certain that some of the marker locus-trait associations significant at $P=0.05$ represent chance events. Nevertheless, it is also certain that many of these associations represent the detection of real genetic effects. Making the significance threshold more stringent would increase the risk of committing Type II errors. Thus, marker locus-trait associations of moderate significance $(0.01<P<0.05)$ are reported here with the awareness that they describe candidate QTL that require additional verification. Others have taken a similar approach (Edwards et al., 1992). Of the 22 marker locus-trait associations in this category, half were not included in the final multilocus models resulting from stepwise multiple regression analysis while all loci with $P$ values $<0.01$ were included in the corresponding multilocus models, for all traits tested.

Of the 39 significant marker locus-trait associations detected based on single-factor ANOVA, only 5 of them were associated with intervals with LOD values higher then 2.0 (Tables 2, 5, and 6 ). This result was partly due to the fact that 14 of the 39 significant markers were detected for loci that were not mapped. In addition, 22 of these 39 significant markers had significance probabilities $>0.01$ and, for markers that were mapped, LOD scores above 2.0 only occurred for those loci with single-factor ANOVA significance probabilities $<0.01$.

Most of the trait distributions deviated significantly from normality. However QTL analyses have often been performed using nonnormal data (Doebley et al., 1990; Freyre et al., 1994; Paterson et al., 1991). The most severely distorted data was for CBB resistance in first trifoliolate leaves, later developed trifoliolate leaves and pods for CBB strain EK-11. However most of the markers or genomic regions associated with resistance in these three plant organs were associated with resistance in more then one plant organ or more then one bacterial strain (Tables 2 and 3). For example, marker BC409 ${ }_{1250}$ was associated with resistance for traits with skewed distributions as well as resistance to $\mathrm{CBB}$ strain Epif-IV and resistance to WB for which the data were normally distributed. This pattern is true also to a similar but lesser extent for markers $\mathrm{AD} 4_{450}, \mathrm{AD} 4_{1150}, \mathrm{~W} 7_{800}$, and K19 ${ }_{450}\left(\right.$ linked to $\left.\mathrm{U} 16_{600}\right)$. The consistency of these significant associations across plant organs, bacterial strains, and the distributional properties of the phenotypic data as well as the consistency of the number of detected QTL with the estimated number of genes (discussed above) indicates that the nonnormality of $\mathrm{CBB}$ resistance data has not hampered QTL detection for these traits in a significant way.

Table 6. Summary of the single-factor ANOVA, interval mapping, and multiple regression analysis of molecular marker and phenotypic data for detection of QTL associated with plant uprightness (PU) and branch density (BD) in a recombinant inbred population derived from the common bean cross, BAC 6 × HT 7719.

\begin{tabular}{|c|c|c|c|c|c|c|c|}
\hline \multirow[b]{2}{*}{ Trait } & \multirow[b]{2}{*}{ Marker $^{2}$} & \multicolumn{2}{|c|}{$\begin{array}{c}\text { Single-factor } \\
\text { ANOVA }\end{array}$} & \multirow{2}{*}{$\frac{\begin{array}{c}\text { Interval } \\
\text { mapping }\end{array}}{\text { LOD }^{w}}$} & \multicolumn{2}{|c|}{$\begin{array}{l}\text { Multiple } \\
\text { regression }\end{array}$} & \multirow{2}{*}{$\begin{array}{c}\text { Linkage } \\
\text { group }^{t}\end{array}$} \\
\hline & & $P>\mathrm{F}^{\mathrm{y}}$ & $R^{2 \mathrm{x}}$ & & $P>\mathrm{F}^{\mathrm{v}}$ & $R^{2 \mathrm{u}}$ & \\
\hline \multirow[t]{3}{*}{$\overline{\mathrm{PU}}$} & $\mathrm{H} 12_{1050}$ & 0.0000 & 16 & & 0.0000 & 16 & UM \\
\hline & $\mathrm{U} 8_{1100}-\mathrm{O} 16_{1200}$ & 0.0015 & 8 & 2.24 & 0.0006 & 8 & 3 \\
\hline & Cumulative $R^{2}$ & & & & & 24 & \\
\hline \multirow[t]{4}{*}{ BD } & $\mathrm{H} 12_{1050}$ & 0.0003 & 10 & & 0.0007 & 9 & UM \\
\hline & $\mathrm{BC} 445_{500}$ & 0.0097 & 5 & & 0.0133 & 4 & 1 \\
\hline & $\mathrm{U} 20_{1050}$ & 0.0152 & 5 & & 0.0136 & 5 & 2 \\
\hline & Cumulative $R^{2}$ & & & & & 18 & \\
\hline
\end{tabular}

\footnotetext{
${ }^{\mathrm{z}}$ Marker or interval significantly associated with trait variation.
}

${ }^{\mathrm{y}}$ Significance levels determined for $\mathrm{F}$ tests based on the single-factor ANOVA for each pairwise comparison of a quantitative trait and marker locus. xPercentage of phenotypic variation explained by the marker locus based on single-factor ANOVA analysis of marker locus-trait associations.

wLOD value at most likely QTL location as determined by Mapmaker QTL.

${ }^{\vee}$ Significance levels determined for $\mathrm{F}$ tests based on multiple regression analysis of marker locus-trait associations for markers found to be significant by single-factor ANOVA $(P<0.05)$.

uPercentage of phenotypic variation explained by each marker locus, for significant $(P<0.05)$ marker locus-trait associations, based on multiple regression analysis.

tLinkage group membership of markers and intervals significantly associated with trait variation for linkage groups as defined in Fig. 1 (UM = unassigned marker). 


\section{Literature Cited}

Ariyarathne, H.M. 1994. Inoculation procedures and heritabilities of the reactions to common bacterial blight in different plant parts in common beans. MS thesis, Univ. of Nebraska, Lincoln.

Arnaud-Santana, E. 1992. Genetics and breeding for resistance to common blight, web blight, and rust diseases in dry beans (Phaseolus vulgaris $\mathrm{L}$.). PhD diss. Univ. of Nebraska, Lincoln.

Arnaud-Santana, E., D.P. Coyne, K.M. Eskridge, and A.K. Vidaver. 1994. Inheritance; Low correlations of leaf, pod, and seed reactions to common blight disease in common beans; and implications for selection. J. Amer. Soc. Hort. Sci. 119:116-121.

Beebe, S.E. and M.A. Pastor-Corrales. 1991. Breeding for disease resistance, p. 561-617. In: A. van Schoonhoven and O. Voysest (eds.). Common beans: Research for crop improvement. CAB Intl., Wallingford, U.K.

Bokosi, J.M., D.P. Coyne, J.R. Steadman, D. O'keefe, and J. Reiser. 1995. Inheritance and associations of specific rust resistance, stem color, leaf pubescence, and flower color in common bean. Annu. Rpt. Bean Improv. Coop. 38:141-142.

Coyne, D.P. 1980. Modification of plant architecture and crop yield by breeding. HortScience 15:244-247.

Coyne, D.P. and M.L. Schuster. 1974. Differential reaction of pods and foliage of beans (Phaseolus vulgaris) to Xanthomonas phaseoli. Plant Dis. Rpt. 58:278-282.

Coyne, D.P. and M.L. Schuster. 1983. Genetics of and breeding for resistance to bacterial pathogens in vegetable crops. HortScience 18:30 36.

Deakin, J.R. and P.D. Dukes. 1975. Breeding snap beans for resistance to diseases caused by Rhizoctonia solani Kuehn. HortScience 10:269-271.

Doebley, J., A. Stec, J. Wendel, and M. Edwards. 1990. Genetic and morphological analysis of a maize-teosinte $\mathrm{F}_{2}$ population: Implications for the origin of maize. Proc. Natl. Acad. Sci. USA 87:9888-9892.

Edwards, M.D., C.W. Stuber, and J.F. Wendel. 1987. Molecular-markerfacilitated investigations of quantitative-trait loci in maize. I. Numbers, genomic distribution and types of gene action. Genetics 116:113-125.

Edwards, M.D., T. Helentjaris, S. Wright, and C.W. Stuber. 1992. Molecular-marker-facilitated investigations of quantitative trait loci in maize. Theor. Appl. Genet. 83:765-774.

Eskridge, K.M. and D.P. Coyne. 1996. Estimating and testing hypotheses about the number of genes using inbred-backcross data. Heredity (In press.)

Freyre, R., S. Warnke, B. Sosinski, and D.S. Douches 1994. Quantitative trait locus analysis of tuber dormancy in diploid potato (Solanum spp.). Theor. Appl. Genet. 89:474-480.

Galvez, G.E., B. Mora, and M.A. Pastor-Corrales. 1989. Web blight, p. 195-209. In: H.F. Schwartz and M.A. Pastor-Corrales (eds.). Bean production problems in the tropics. Centro Internacional de Agricultura Tropical (CIAT), Cali, Colombia.

Harter, L.L. and W.J. Zaumeyer. 1944. A monographic study of bean diseases and methods for their control. U.S. Dept. of Agr. Tech. Bul. 868.

Kosambi, D.D. 1944. The estimation of map distances from recombination values. Ann. Eugenics 12:172-175.

Lander, E.S. and D. Botstein. 1989. Mapping Mendelian factors underlying quantitative traits using RFLP linkage maps. Genetics 121:185-199.

Lander, E.S., P. Green, J. Abrahamson, A. Barlow, M.J. Daly, S.E. Lincoln, and L. Newburg. 1987. MAPMAKER: An interactive computer package for constructing primary genetic linkage maps with experimental and natural populations. Genomics 1:174-181.

Melchinger, A.E. 1990. Use of molecular markers in breeding for oligogenic disease resistance. Plant Breeding 104:1-19.

Miklas, P.N., J.R. Stavely, and J.D. Kelly. 1993. Identification and potential use of a molecular marker for rust resistance in common bean.
Theor. Appl. Genet. 85:745-749.

Nelson, R.R. 1978. Genetics of horizontal resistance to plant diseases. Annu. Rev. Phytopathol. 16:359-378.

Nodari, R.O., S.M. Tsai, R.L. Gilbertson, and P. Gepts. 1993a. Towards an integrated linkage map of common bean. II. Development of an RFLP-based linkage map. Theor. Appl. Genet. 85:513-520.

Nodari, R.O., S.M. Tasi, P. Guzman, R.L. Gilbertson, and P. Gepts. 1993b. Toward an integrated linkage map of common bean. III. Mapping genetic factors controlling host-bacteria interactions. Genetics 134:341-350.

Pastor-Corrales, M.A. and G.S. Abawi. 1988. Bean accessions with resistance to Rhizoctonia solani under field conditions in Colombia. Turrialba 38:87-92.

Paterson, A.H., S. Damon, J.D. Hewitt, D. Zamir, H.D. Rabinowitch, S.E. Lincoln, E.S. Lander, and S.D. Tanksley. 1991. Mendelian factors underlying quantitative traits in tomato: comparison across species, generations, and environments. Genetics 127:181-197.

Sanders, J.H. and H.F. Schwartz. 1980. Bean production problems and pest constraints in Latin America, p. 1-14. In: H.F. Schwartz and G.E. Galvez (eds.). Bean production problems. Centro International de Agricultura Tropical (CIAT), Cali, Columbia.

Saettler, A.W. 1989. Common bacterial blight, p. 261-283. In: H.F. Schwartz and M.A. Pastor-Corrales (eds.). Bean production problems in the tropics. Centro International de Agricultura Tropical (CIAT), Cali, Columbia.

Schafer, J.F. and A.P. Roelfs. 1985. Estimated relation between numbers of urediniospores of Puccinia graminis f. sp. tritici and rates of occurrence of virulence. Phytopathology 75:749-750

Schwartz, H.F. and J.R. Steadman. 1989. White mold, p. 211-230. In: H.F. Schwartz and M.A. Pastor-Corrales (eds.). Bean production problems in the tropics. Centro International de Agricultura Tropical (CIAT), Cali, Columbia.

Silva, G.H. and R.W. Hartmann. 1982. Inheritance of resistance to Rhizoctonia solani Kuhn in snap beans (Phaseolus vulgaris L.). J. Amer. Soc. Hort. Sci. 107:653-657.

Skroch, P. and J. Nienhuis. 1995. Qualitative and quantitative characterization of RAPD variation among snap bean (Phaseolus vulgaris) genotypes. Theor. Appl. Genet. 91:1078-1085.

Stavely, J.R. and M.A. Pastor-Corrales. 1989. Rust, p. 159-194. In: H.F. Schwartz and M.A. Pastor-Corrales (eds.). Bean production problems in the tropics. Centro International de Agricultura Tropical (CIAT), Cali, Columbia.

Steadman, J.R., J. Beaver, M. Boudreau, D.P. Coyne, J. Groth, J. Kelly, M. McMillan, R. McMillan, P. Miklas, M. Pastor-Corrales, H. Schwartz and J. Stavely. 1995. Progress reported at the 2 nd international bean rust workshop. Annu. Rpt. Bean Improv. Coop. 38:1-10.

Tanksley S.D., N.D. Young, A.H. Paterson, and M.W. Bonierbale. 1993. RFLP mapping in plant breeding: new tools for an old science. Bio/ Technology 7:257-264.

Valladares-Sanchez, N.E., D.P. Coyne, and M.L. Schuster. 1979. Differential reaction of leaves and pods of Phaseolus germplasm to strains of Xanthomonas phaseoli and transgressive segregation for tolerance from crosses of susceptible germplasm. J. Amer. Soc. Hort. Sci. 104:648654

Vallejos, C.E., N.S. Sakiyama, and C.D. Chase. 1992. A molecular marker-based linkage map of Phaseolus vulgaris L. Genetics 131:733740 .

Webster, D.M. and P.M. Ainsworth. 1988. Inheritance and stability of a small pustule reaction of snap beans to Uromyces appendiculatus. $\mathbf{J}$. Amer. Soc. Hort. Sci. 113:938-940.

Williams, J.G.K., A.R. Kubelik, K.J. Livak, J.A. Rafalski, and S.V. Tingey. 1990. DNA polymorphisms amplified by arbitrary primers are useful as genetic markers. Nucleic Acids Res. 18:6531-6535. 